\title{
O SEGMENTO DE MODA AFRO- BRASILEIRA: Conceitos, Estruturas e Narrativas
}

Afro-brazilian fashion sector: Concepts;Strucures and Narrative

\section{Patrícia Helena Campestrini Harger}




\section{O SEGMENTO DE MODA AFRO-BRASILEIRA: Conceitos, Estruturas e Narrativas}

Afro-brazilian fashion sector: Concepts; Strucures and Narrative

Patrícia Helena Campestrini Harger

\section{Resumo}

O intuito desse artigo é apresentar os conceitos da moda afro-brasileira e afirmala como um segmento de mercado efetivo. Muitos não têm conhecimento desse nicho, mas ele atua no mercado de moda carregando os pilares de nossa cultura. Para tornar a pesquisa mais fortalecida foram analisadas vinte marcas que desenvolvem a moda afro-brasileira e como elas estão conectadas com essa cultura quanto às referencias, cores, estilos e estruturas. A pesquisa está baseada nos fundamentos da relação entre a identidade das estilistas representantes do segmento e a moda.

Palavras- chave: Afro-brasileiro.

Segmento de Moda. Estilistas.

\begin{abstract}
The purpose of this article is to present the Afro-Brazilian fashion concepts and claims it as an effective market segment. Many people are unaware about this niche, but it operates in the fashion market carrying the pillars of our culture. To strengthen this research, twenty brands that develops the Afro-Brazilian fashion were analyzed and how they are connected with this culture related to its colors, styles and structures. The research is based on the fundamentals of the relationship between the identity of the segment's representatives stylists and fashion.
\end{abstract}

Keywords: Afro-Brazilian. Fashion Segment. Fashion Designers. 


\section{Introdução}

A moda está direcionada para o atendimento de diferentes interesses e grupos sociais, sendo assim, as construções das roupas e dos acessórios que compõem a moda afro-brasileira recebem intensa influência da cultura brasileira e da cultura africana que podem ser observadas por meio dos diferentes elementos aplicados ao vestuário, como o grafismo marcante, cores fortes, aspectos religiosos e culturais, apresentados pela pesquisa de marcas de moda afro-brasileira e suas principais características estéticas. Dentro desse trabalho o termo "moda afro-brasileira" faz alusão não somente a tendência de uma marca ao referenciar sua criação e sim estilistas que dedicam sua carreira profissional se voltando às questões que vão além do vestir, mas que fazem parte de suas histórias pessoais, utilizando a roupa como um suporte mantenedor de sua ancestralidade, suas origens, seus ideais, alinhamentos políticos e sociais. Para tanto, a moda afro-brasileira necessita se manter da cultura afro-brasileira, não somente como uma tendência passageira.

Assim, as estilistas afro-brasileiras, ao desenvolverem suas coleções, se voltam para suas raízes culturais e ancestrais transmitindo seus valores pessoais e sociais em forma de produtos de moda, tentando inseri-los em um mercado que muitas vezes não está aberto às questões que estão embutidas na moda afro-brasileira, enfrentando da mesma maneira o preconceito que sofrem os afrodescendentes até os dias atuais.

Enfatiza-se ainda que os elementos valorizados nas roupas e nos acessórios da moda afro-brasileira são capazes de desempenhar um papel importante na construção da identidade cultural. Com a valorização das matrizes africanas, há o resgate dos costumes e das crenças dos antepassados, é fato que não podemos afirmar que toda população negra se identifique com suas raízes através da moda afro-brasileira, pois cada estilista possui uma maneira de afirmar a identidade cultural por meio da roupa, e as escolhas do vestir são individuais, mas é possível que haja um fortalecimento dessa cultura, permitindo que quem faz o uso dessa moda identifique valores comuns. Neste contexto, este estudo busca analisar como o segmento de moda afro-brasileira esta inserido no mercado de moda atual, quais são os atores sociais desse segmento, como eles referenciam suas criações através de cores, estruturas e estilos e para quem está destinada essa moda. 


\section{QUE É A MODA AFRO-BRASILEIRA}

A moda pode expressar o modo de se vestir, a personalidade, os interesses e outras características que demonstram o tempo histórico em que os seres humanos se encontram inseridos, demonstrando comportamentos e permeando processos comunicativos e culturais. Assim, a moda funciona como um mediador de papeis dentro da sociedade. Neste contexto, a estética da moda afro-brasileira se relaciona com a moda, com o mercado, com a sociedade e principalmente com os afro-brasileiros, assumindo essa identidade através das roupas, acessórios, cabelos e comportamentos.

A moda volta-se para as raízes antropológicas das civilizações, abrangendo transformações em vários setores da sociedade. Trata-se de uma linguagem sociocultural indo além do vestir, adentrando-se no "universo de tecnologias da beleza, design de superfície, design de joias e bijuterias, decoração, gostos de consumo cultural etc.” (SANT'ANNA, 2009, p. 50).

Cabe ressaltar que os povos são diferenciados pelas suas características culturais que envolvem os fatores como crenças, costumes, vestimentas, alimentação, idiomas e outros elementos que são considerados diferenciais para a sociedade. Cada grupo social consegue interagir com determinado ambiente físico quando seus aspectos culturais se encontram inseridos no mesmo. Dessa maneira, uma vez que esses aspectos culturais são transformadores da sociedade e são inerentes ao desenvolvimento humano, podem desenvolver novos atributos de sobrevivência para os indivíduos, demonstrando que o ser humano é capaz de vivenciar outras culturas por meio do aprendizado de diferentes idiomas e funções (SAHLINS, 1979).

Tratando desses aspectos, podemos ressaltar a moda como um fenômeno cultural e um meio de comunicação que pode ser usado como forma de construção de identidades, atendendo a desejos e diferentes necessidades, mas que está inserida em um contexto cultural. Deste modo, a moda afro-brasileira se fixa na cultura brasileira, e pode ser um suporte de comunicação de outras culturas como a indígena ou africana, construindo assim sua própria identidade plural. A moda afro se apresenta como um importante suporte da cultura afro-brasileira, o qual pode transmitir por meio da roupa a mistura que tivemos em nosso país, principalmente a africana, indígena e portuguesa, mas não somente essas, e sim todas que fazem parte de nossa base cultural. 
Ao tratarmos dessa moda e afirma-la como um segmento efetivo dentro do mercado brasileiro, não podemos deixar de falar de quem são os atores sociais, ou seja, aqueles que desenvolvem, criam e constroem suas narrativas por meio dessa moda - os estilistas.

O papel do estilista é fundamental quando tratamos da moda afro-brasileira, pois o estilista é o criador que faz suas coleções a partir de sua própria experiência de vida e como Pierre Bourdieu (1983, p. 154-161) compara o estilista a um pintor: "se pensarmos na pintura de vanguarda, na pintura conceitual, compreenderemos que é fundamental que o criador possa se criar como criador ao ter o discurso que faça seu poder criador ser acreditado", nesse contexto a individualidade de cada estilista no ato de sua criação deixa marcas em suas coleções.

Existe uma divergência entre o estilista de moda afro-brasileira e o estilista de moda brasileira, não no ato de criar em si, mas no sentido das referencias utilizadas como base das coleções.

Para descrever a principal diferença entre moda afro-brasileira e moda brasileira primeiro precisamos entender como o mercado de moda está dividido, podemos observar na Figura 1.

Figura 1 - Inserção da moda afro-brasileira

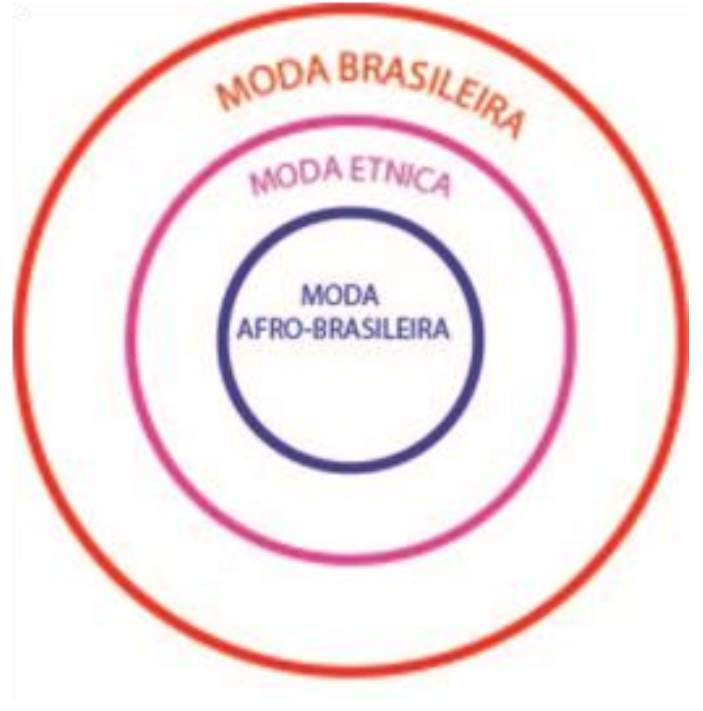

Fonte: autora

O mercado de Moda brasileira está subdividido em segmentos que podem ser moda praia; moda plus-size; moda festa; moda streetwear; etc. A moda étnica é um 
desses segmentos. Ela é determinada por ser uma moda cultural que engloba vários estilos geralmente ligados as raízes de algum grupo étnico, como por exemplo, tribos indígenas, povos egípcios, peruanos, alemães, espanhóis, etc. Portanto a estética das roupas criadas dentro do segmento de moda étnica está referenciada em algum grupo étnico.

Nesse contexto a moda afro-brasileira também está inserida na moda étnica, pois faz referencia às raízes culturais Africana e Brasileira, tornando-se um segmento com identidade própria.

\section{AS ESTRUTURAS E NARRATIVAS DA MODA AFRO-BRASILEIRA}

Para afirmar que a moda afro-brasileira é um segmento atuante dentro do mercado de moda é necessário trazer mais informações de como essa moda se apresenta, quais suas estruturas, cores, estilos, formas, quem são seus estilistas e a importância da cultura afro-baiana nesse nicho. Para tanto foram selecionados vinte profissionais que desenvolvem especificamente roupa afro-brasileira, sendo três deles entrevistados para que pudessem dar mais informações de seu processo criativo e de como apoiam suas raízes culturais e ancestrais dentro das coleções desenvolvidas (Tabela 1).

Tabela 1 - Estilistas da moda afro-brasileira

\begin{tabular}{|l|l|l|}
\hline \multicolumn{2}{|c|}{ MARCA } & \multicolumn{2}{c|}{ CSTILISTA } & Salvador/BA \\
\hline Goya Lopes & Goya Lopes & Salvador/BA \\
\hline Ifá veste & Saraí Reis & Salvador/BA \\
\hline Negrif & Madalena Cardoso & São Paulo/SP \\
\hline Xongani Arte com tecido & Cris Mendonça e Ana Paula & Rio de Janeiro/RJ \\
\hline Empório afro moda & Fatima Negran & Botucatu/SP \\
\hline Botuafrica & Mônica Nador/Renato Imbroisi & Rio de Janeiro/RJ \\
\hline Balaco & Julia Vidal & Belo Horizonte/MG \\
\hline Moda arte e design & Enia & Salvador/BA \\
\hline Monica Anjos & Monica Anjos & Salvador/BA \\
\hline N'Black & Najara Black & Hortolândia/SP \\
\hline Criolê & Isabel Cristina & Brasília/DF \\
\hline Bazafro & Lydia Garcia & Salvador/BA \\
\hline By yosh & Washinton José & Belo Horizonte/MG \\
\hline TC arte & Makota Kizandembu & Salvador/BA \\
\hline Marcia Ganem & Marcia Ganem & São Paulo/SP \\
\hline Pegada preta & Cynthia Mariah & \\
\hline
\end{tabular}




\begin{tabular}{|l|l|l|}
\hline Chica da Silva & Marcial Avila & Belo Horizonte/MG \\
\hline Pretto Básico & Marcio Vaz & Rio de Janeiro/RJ \\
\hline Moyó Atelie & Deia Talamungongo/Yuri Tawaresi & Brasília/DF \\
\hline Katuka Africanidades & Renato Carneiro & Salvador/BA \\
\hline
\end{tabular}

Fonte: Elaborado pela autora

Na tabela estão relacionados os estilistas que desenvolvem moda afro-brasileira, a maioria pode ser localizada por possuírem site da marca ou rede social. Existem muitos outros espalhados pelo Brasil, mas que não puderam ser localizados por falta de dados. As cidades que possuem maior concentração de população afro-brasileira também são as que possuem maiores numero de profissionais que se dedicam a essa moda.

Outro ponto importante de abordar acerca do assunto são os aspectos dos elementos aplicados na roupa afro-brasileira. Através das falas das estilistas, Julia Vidal ${ }^{1}$ que é fundadora da marca Julia Vidal Moda Étnica que está localizada na cidade do Rio de Janeiro, Goya Lopes ${ }^{2}$ que é design, artista, estilista e pioneira no segmento de moda afro-brasileira tem sua loja em Salvador no Pelourinho, mas atua em diferentes segmentos além da moda como forma de expandir seu trabalho e Madalena Cardoso ${ }^{3}$ que é fundadora e estilista da marca Negrif situada na cidade de Salvador; podemos ter uma ideia de como elas utilizam a simbologia da cultura afro nas coleções criadas (Figura 2).

\footnotetext{
${ }^{1}$ http://www.juliavidal.com.br/

2 https://goyalopes.com.br/

${ }^{3}$ https://www.facebook.com/lojanegrif/?fref=ts
} 
Figura 2: da esquerda para direita; Julia Vidal, Goya Lopes e Madalena Cardoso

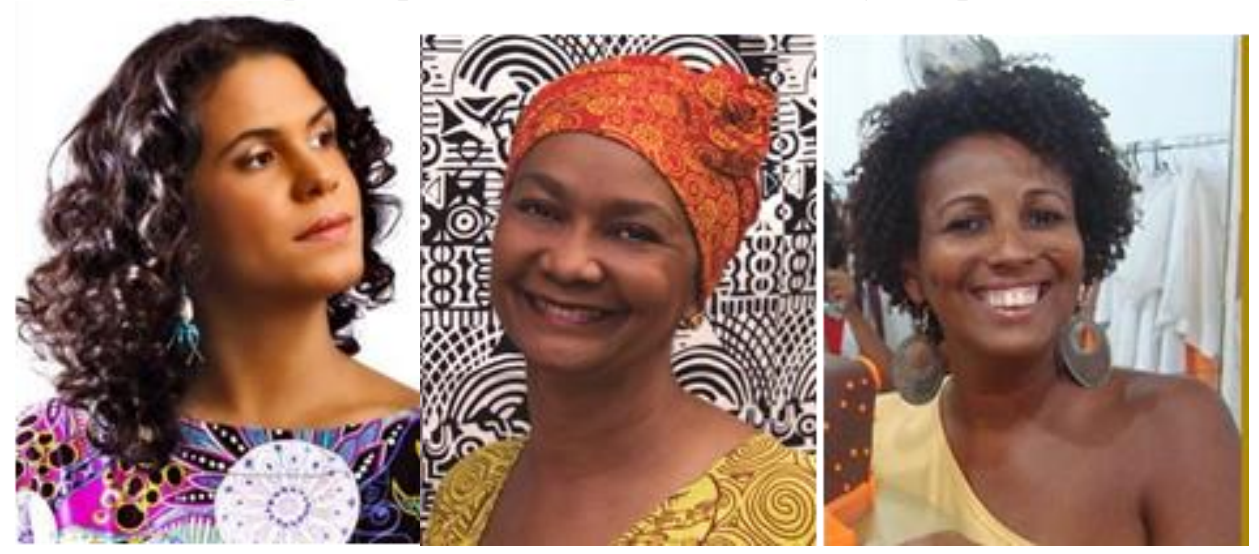

Fonte: Google Imagens

Os elementos mais utilizados por Julia Vidal apresentam relação com a cultura brasileira. A estilista relata que é fundamental compreender a diferença entre vender um produto e vender cultura. Para tanto, afirma que suas roupas transmitem uma história. É um valor agregado, no qual o consumidor adquire um produto utilitário, porém que possui uma série de outros atributos. Além disso, as referências de material estão muito conectadas com essas bases, porque através do material é possível estabelecer uma conexão com a cultura afro-baiana. Como exemplo, a estilista citou que realiza bordados com palha da Costa, uma matéria prima pouco conhecida no Rio de Janeiro, porém bastante popular na Bahia.

No Rio de Janeiro o trabalho de Júlia Vidal engloba mais a questão de modelagem, de comportamento, de atitude e as raízes étnicas, havendo também uma pesquisa baseada em tingimentos naturais. Há um trabalho de sustentabilidade que vai desde a escolha do material até as ideias da criação da coleção em fazer uma moda que seja menos agressiva ao meio ambiente, já que a mesma se encontra associada aos aspectos culturais dos povos, ao respeito à natureza, à ancestralidade e a uma história. Então é fundamental que os processos de produção não agridam o meio ambiente. Dessa maneira, a estilista faz uso de matérias-primas natural e não sintéticas, como aquelas também usadas por povos indígenas na confecção de suas utilidades domésticas, suas pinturas corporais e suas roupas como o jenipapo, o barro, a cerâmica, o urucum e o açafrão, que para ela são muito importantes, pois sua família possui origens indígenas. 
Isso estabelece uma ligação com seus antepassados e fortalece os pilares étnicos culturais de sua produção de moda.

Júlia Vidal afirma que seu trabalho é repleto de referências da cultura afrobaiana, carioca e indígena estando realmente construídos sobre esses três pilares. Da cultura afro-baiana, ela traz elementos na modelagem que são muito vistos como amarrações e diferentes acabamentos, havendo inclusive uma coleção inspirada nas baianas, que necessitou de uma pesquisa específica simbólica para o entendimento dos balangandãs, que é parte dos acessórios e vestimenta da baiana.

Vidal ainda cita que existem vários vestidos de sua coleção que a modelagem é inspirada no pano da $\operatorname{Costa}^{4}$, que se remete ao costume dos escravos de amarrar de forma diferenciada os tecidos, e expressando assim traços identitários e étnicos. Suas coleções buscam ainda inspiração na representação da população negra na sociedade escravocrata; na hierarquia interna e externa; como eles se apresentavam para sociedade quando escravos; como eram também internamente as funções que os negros ocupavam nas senzalas e casa grande; os status sociais que existiam dentro da cultura africana no Brasil e afro-brasileira.

Além disso, as coleções de Julia também estão inspiradas na mulher contemporânea; necessitando de um estilo mais despojado, porém elegante. Sua coleção também está representada pela mulher que viaja e precisa de vestimentas constituídas por tecidos que amassam menos; e no lifestyle $e^{5}$ carioca. Desse modo, a estilista cita uma série de situações que inspiram o desenvolvimento de suas coleções e que podem impactar nos traços de individualidade e a identidade de cada pessoa. A mesma ressalta que procura focar em suas próprias raízes, de Belém e da ilha de Marajó, utilizando acessórios e elementos na estamparia demonstrando assim sua visão do mundo e como ele é processado em seu interior e como deve ser externalizado no mercado.

Para a estilista e design Goya Lopes é importante considerar que a baiana não é uma construção africana, pois é brasileira, assim como os blocos afros da Bahia, como também do Rio de Janeiro, as escolas de samba, e outros aspectos da cultura brasileira. Para ela, não se pode desconsiderar todo esse contexto ao criar moda afro-brasileira,

\footnotetext{
${ }^{4}$ Pano da Costa: é um tecido retangular liso ou com estampas de motivos africanos, que as mulheres na África utilizam enrolados ao corpo de diferentes formas, aqui no Brasil o traje foi incorporado pelas mulheres negras e hoje é utilizado tanto em cerimonias religiosas onde é dotado de significado, como no dia-a-dia como acessório.

${ }^{5}$ Lifestyle: Corresponde ao dia-a-dia das pessoas, ou no estilo de vida que estão acostumadas a viver.
} 
mas também é preciso separar o que é moda afro e o que se enquadra dentro da religiosidade para não haver a desassociação da referência étnica.

Segundo Goya, existe elementos fortes que estão na religiosidade, na culinária e nas artes. Para ela, a culinária é um potencial muito grande de se fazer construir uma referencia mais moderna e contemporânea que podem ser utilizadas nas referencias de criação de coleções da moda afro-brasileira. Os elementos da África em si proporcionam um vasto conteúdo para essas criações de moda, assim como a cultura brasileira e por fim a cultura baiana.

A estética da moda afro-brasileira criada por Goya Lopes é transmitida com base na tecelagem, na ancestralidade, na africaneidade, na afro-brasilidade, respeitando a questão cronológica dos negros no Brasil, a solidariedade e o cotidiano.

Quando observadas as imagens da figura 3 e figura 4 que estão inseridas no livro de Goya ${ }^{6}$, pode-se ter a impressão de serem meras estampas, mas ao manter a visão mais profunda é possível notar que cada elemento faz referencia a uma história, um símbolo da ancestralidade, do cotidiano, da culinária ou da religião que estão ao mesmo tempo dentro de um contexto relacionado a afro-brasilidade (Figura 3 e Figura 4).

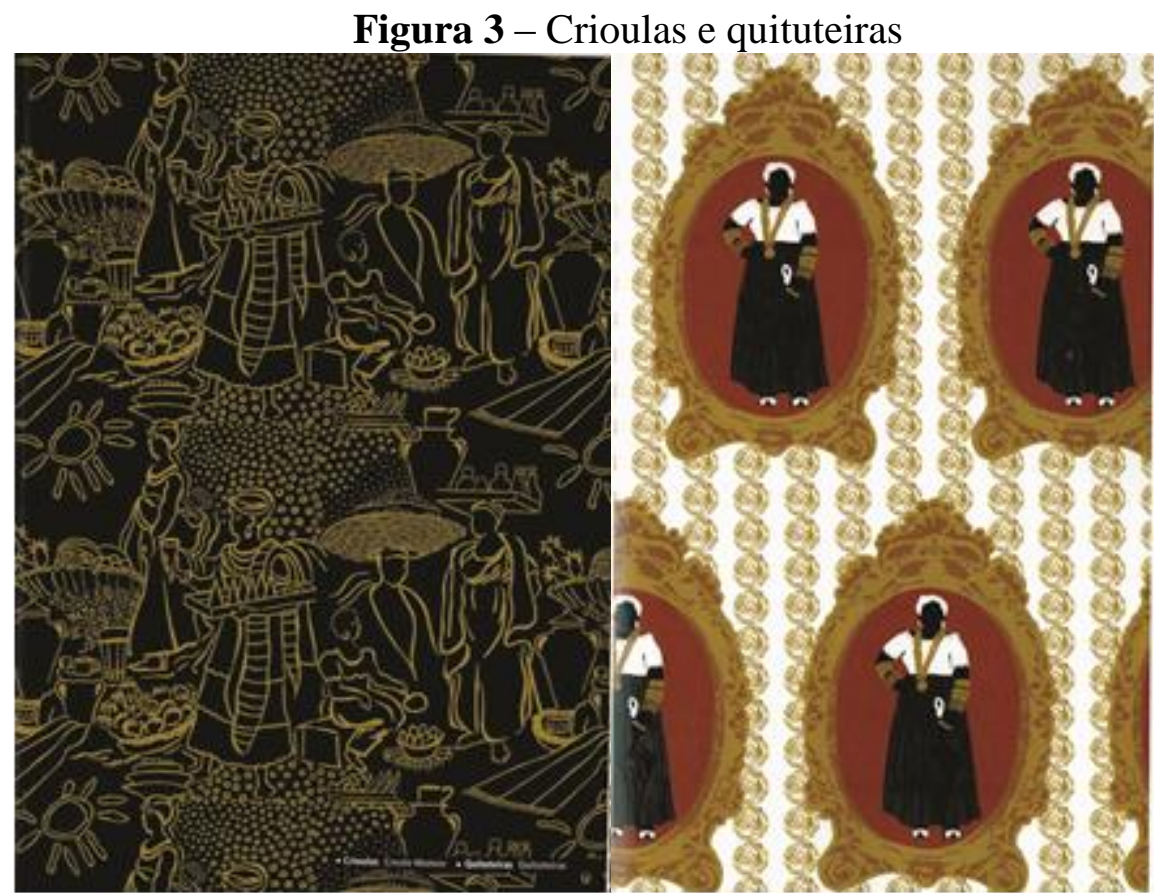

Fonte: Lopes e Falcon (2010, p. 67-68)

\footnotetext{
${ }^{6}$ LOPES, Goya; FALCON, Gustavo. Imagens da Diáspora. Bahia: Solisluna Editora, 2010.
} 


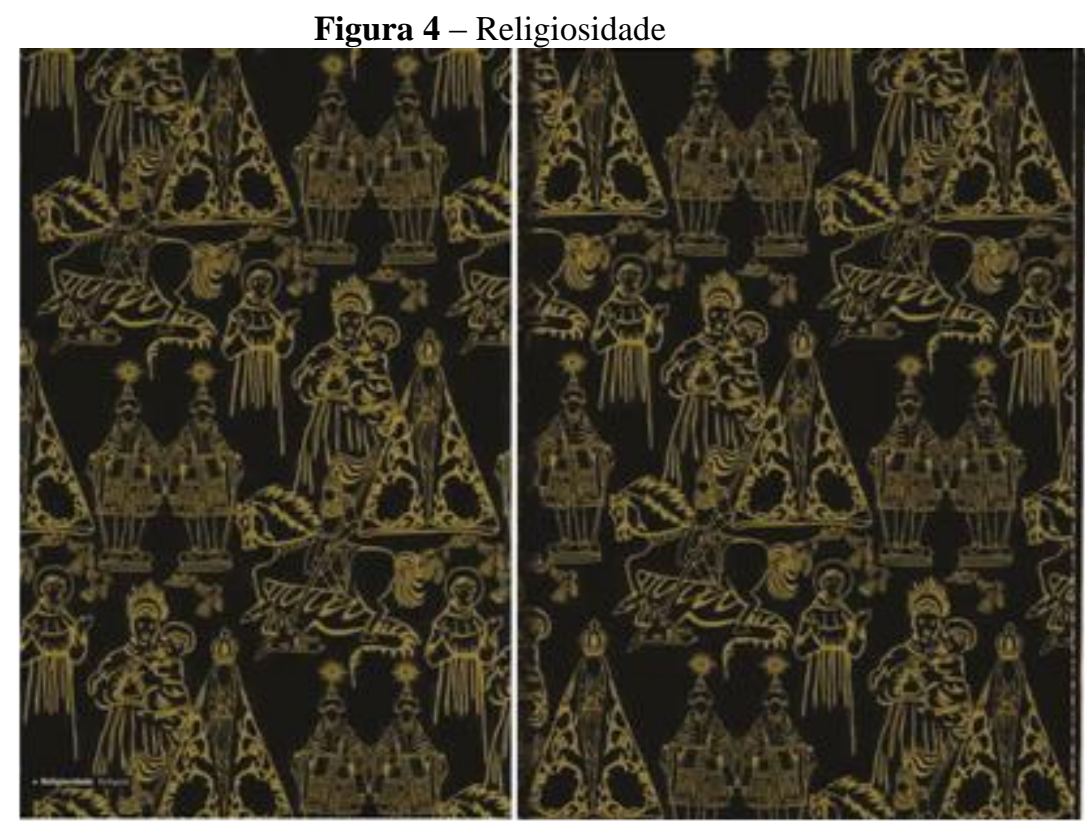

Fonte: Lopes e Falcon (2010, p. 77-78)

$\mathrm{Na}$ opinião da estilista Madalena Cardoso, os elementos que caracterizam a moda afro-brasileira são formados pelo conteúdo histórico que se deu do continente africano para o Brasil com a escravidão, a mistura de povos, dos costumes, dos idiomas, do uso de retalhos e trapos, do reaproveitamento, do que foi necessário improvisar, criar, e então a moda afro-brasileira pode ser constituída por uma variedade de cores e modelagens amplas. Para a estilista o povo que caminha pelas ruas já desfila sua própria identidade e isso proporciona ao criador uma ideia sobre o que combina com cada grupo. As referencias de elementos utilizados nas coleções da Negrif estão inspirados nas características estéticas da mulher negra, no entanto são as mulheres do dia a dia ditam onde os estilistas devem buscar a real inspiração segundo Madalena.

Fazendo referência ao que as três estilistas entrevistadas apontaram a respeito dos elementos afro-brasileiros utilizados em suas coleções, podemos observar que essas marcas pesquisadas que se identificam como fazendo parte do segmento de moda afrobrasileira, e utilizam elementos variados característicos da mistura de elementos africanos com brasileiros nas estampas contidas nas peças de roupa.

Portanto, uma característica marcante da moda afro-brasileira são as peças estampadas, que variam de estampas localizadas, que são aquelas que possuem desenhos bem definidos localizados, geralmente em uma parte específica da peça, frente, costas, manga entre outras; ou estampas corridas, que são estampas em que o 
desenho está presente em um todo, podendo ser desenhos que se repetem ao longo do tecido, ou mesmo desenhos que se complementam, contam uma história através da extensão do tecido.

Outra observação que pode ser feita através das pesquisas das marcas relacionadas no artigo é com relação ao estilo de cada marca. Identificou-se que as religiões africanas são bastante referenciadas, uma vez que as marcas fazem uso da simbologia africana em suas vestimentas através da utilização de estampas, amarrações e modelagens amplas. Assim, podemos dividir essas marcas dentro de basicamente três estilos: estilo contemporâneo, estilo religioso e estilo ancestral. Nesse contexto utilizase o termo estilo para traduzir qual a referencia em que a marca se conecta.

Estilo Contemporâneo - Tem sua estética voltada para o universo da moda contemporânea, mantem a identidade afro-brasileira principalmente através das estampas das peças como mostrado nas Figuras 5 e 6.

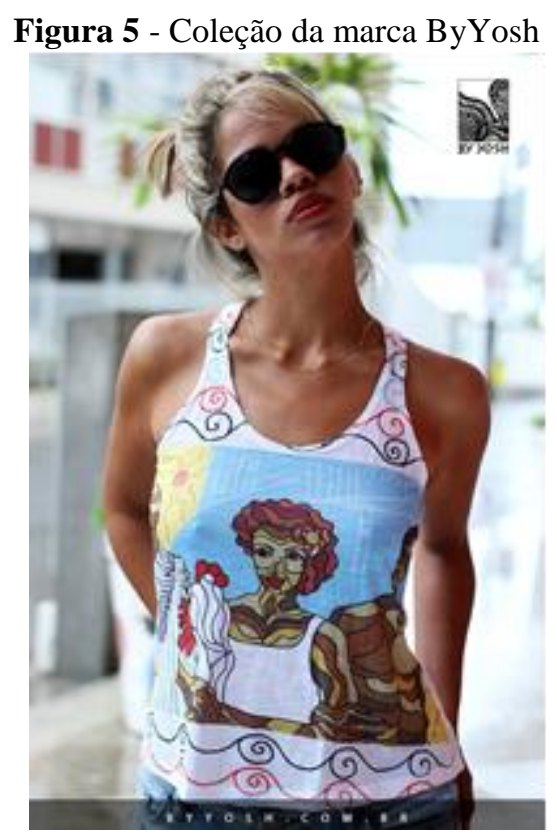

Fonte: Disponível em: <https://www.facebook.com/lojabyyosh/timeline> 


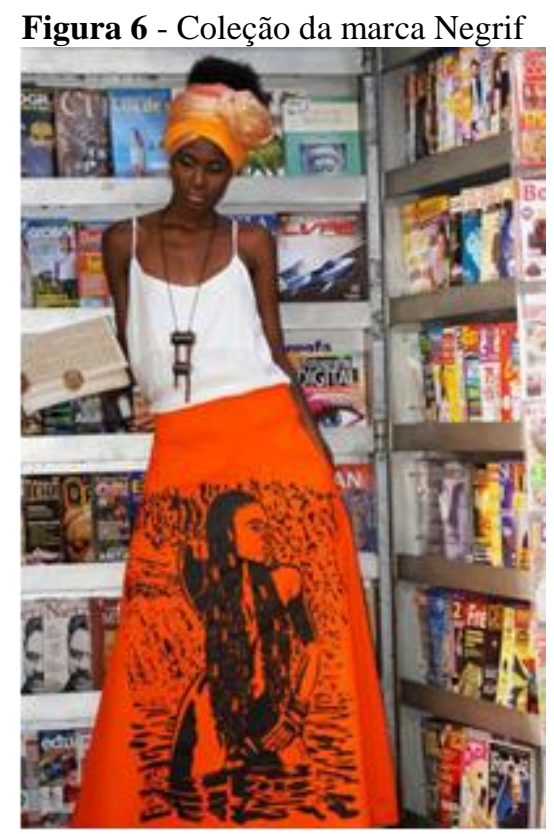

Fonte: Disponível em: <https://www.facebook.com/mada.negrif?fref=ts>

Estilo Religioso- Tem maior conexão com a religião. São peças que podem ser usadas no dia-a-dia ou podem ser usadas para ir a cultos religiosos ou eventos ligados à cultura afro-brasileira. Geralmente, são peças artesanais produzidas à mão e que oferecem exclusividade para o cliente. Não são especificamente roupas para mães ou pais de santo, mas sim para quem participa dos cultos afro-brasileiros ou se identifica com o estilo. Como exemplo nas Figuras 7 e 8 abaixo:

Figura 7 - Lydia Garcia da marca Bazafro em evento Festival de Latinidades

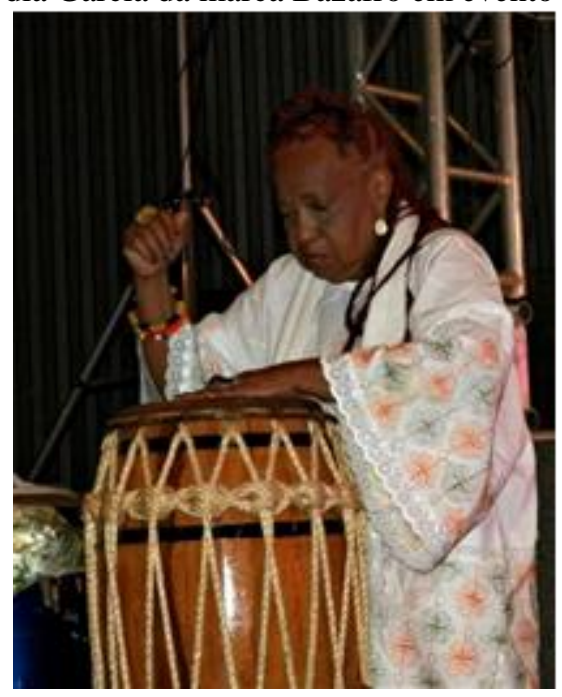

Fonte: Disponível em: 〈https://www.facebook.com/lydiabazafro> 
Figura 8 - Makota Kizandembu em Cortejo de Omulu

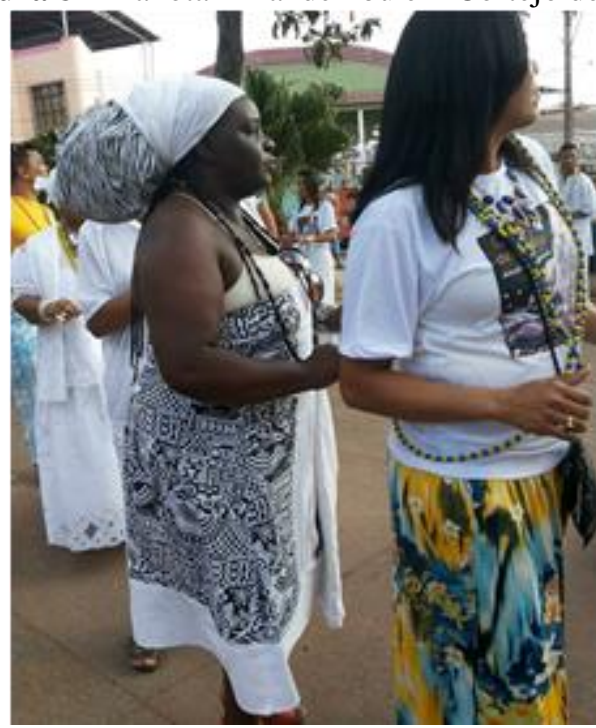

Fonte: Disponível em: 〈https://www.facebook.com/makotakizandembu?fref=ts $>$

Estilo Ancestral- Está mais focado em peças que remetem a África ${ }^{7}$, geralmente possuem modelagens amplas, amarrações e os tecidos utilizados são bastante estampados e coloridos, conforme apresentado nas Figuras 9 e 10:

\footnotetext{
${ }^{7}$ A África que está sendo tratada é no sentido geral, sabe-se que o continente Africano é muito grande e que possui uma diversidade cultural imensa, mas dentro desse trabalho apresentado a referencia africana remete a cultura dos escravos trazidos para o Brasil vindos de vários pontos do continente africano: da costa ocidental, entre o Cabo Verde e o da Boa Esperança; da costa oriental, de Moçambique; e mesmo de algumas regiões do interior.
} 
Figura 9 - Vestido desenvolvido por Monica Anjos

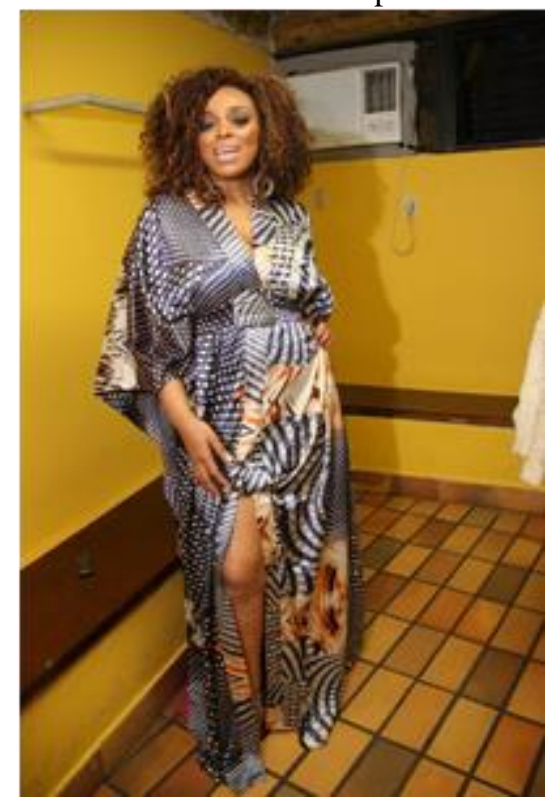

Fonte: Disponível em: 〈https://www.facebook.com/estilistamonicaanjos/timeline>

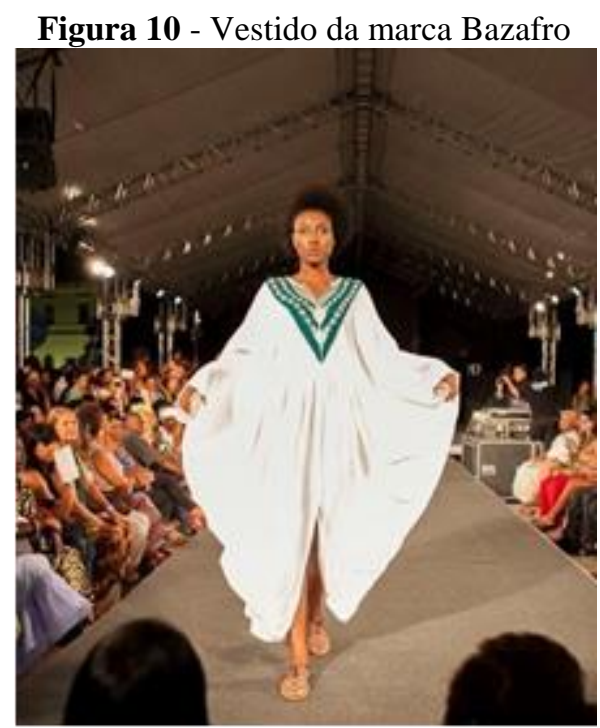

Fonte: Disponível em: <https://www.facebook.com/lydiabazafro/photos>

As imagens apresentadas são apenas exemplos de como as marcas apoiam as referencias estéticas culturais nas criações de suas peças. Dentre as marcas pesquisadas observa-se que nenhuma delas esta fixada em apenas um estilo. As estilistas transitam no universo da criação entre diferentes estilos dependendo dos temas e inspirações que escolhem para criar uma dada coleção. Ora adotam estilos mais contemporâneos ou religiosos ora mais ancestrais. Porém em todas as marcas as questões da identidade afrobrasileira são um posicionamento bem definido. 
Entre os elementos empregados nas roupas dos estilistas, demonstra-se que há a valorização das características das mulheres negras através das estampas aplicadas nas peças. Além das estampas observadas podemos acrescentar que a utilização de algumas referências é recorrente como os elementos geométricos; uso de peles, pedras, fibras, aplicações, máscaras e estampados; símbolos do candomblé; do hip hop; o grafite; fitas de poliamida; macramê ${ }^{8}$; moulagem ${ }^{9}$, entre outros elementos que são símbolos da moda afro-brasileira.

Outra análise que pode ser feita ao observarmos algumas peças apresentadas é a necessidade de afirmação evidenciada através de frases, rostos negros, cabelos blacks em estampas nas roupas, no sentido de demonstrar seu orgulho de ser negro (Figura 11). Nesse contexto podemos citar esse processo como uma construção de identidade que pode ser "um conjunto mais ou menos integrado de práticas que um indivíduo abraça, não só porque essas práticas preenchem necessidades utilitárias, mas porque dão forma material a uma narrativa particular de auto identidade" (GIDDENS, 2002, p. 79).

Figura 11 - camiseta da marca N’Black- “É o Poder Aceita Porque Dói Menos”

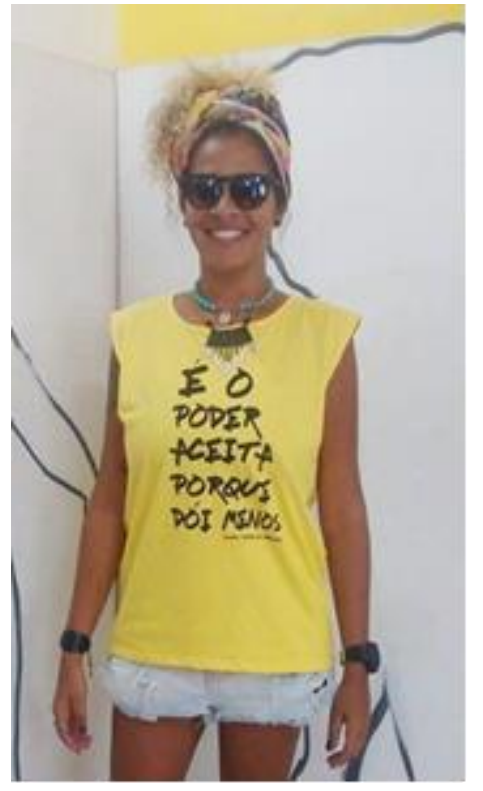

Fonte: Disponível em: <https://www.facebook.com/302935086390588/photos/a.339331406084289.99513.302935086390588/13 $15407108476709 /$ ?type $=3 \&$ theater $>$

\footnotetext{
${ }^{8}$ Forma de tecer fios manualmente através de amarrações, trançados e nós

${ }^{9}$ Moulagem: modelagem tridimensional, feita com o tecido colocado junto ao corpo ou pregado em manequim.
} 
Ao olhar para os estilistas como produtores de objetos de moda podemos afirmar que de certa forma a criação desses estilos é uma proposta de identidade que está sendo apresentada aos consumidores. Através de suas historias, e valores esses estilistas se reconhecem em suas criações. "A roupa é um meio de auto exibição, mas também se relaciona diretamente à ocultação/revelação a respeito das biografias pessoais — liga as convenções a aspectos básicos da identidade" (GIDDENS, 2002, p. 63).

Assim, ao criarem suas peças, esses estilistas apresentam à sociedade uma proposta identitária, um estilo de vida em que acreditam. Essas questões também são tratadas por Anthony Giddens que afirma que a seleção ou criação de estilos de vida é influenciada por pressões de grupo e pela visibilidade de modelos, no entanto os estilistas por serem pessoas públicas pensam em serem vetores de historias que precisam ser contadas e narradas, que precisam ser lembradas. Esses estilistas estão construindo imagens de si, são imagens publicas, estão comunicando coisas. Estão se alinhando a formas de pensar a sociedade como questões da sustentabilidade da valorização da estética da manutenção das tradições e símbolos. Através de discursos é que os estilistas se expressam, por meio de formas nessas roupas, ganhando força e alcance.

De fato, o estilista está assim demonstrando sua posição dentro da sociedade brasileira, seu orgulho de ser negro e negra, que através das suas criações, consegue comunicar sua aceitação dentro desse universo, permitindo assim, que outras pessoas possam também se identificar com esse posicionamento. Algumas das falas das estilistas pesquisadas estão em consonância com essa ideia: ‘

"No produto busco contar a nossa história de uma forma alegre, bonita" (Goya Lopes).

"A minha bandeira como afrodescendente era criar uma moda da cultura afro pra todos, e realmente a gente tem essa questão, que é uma moda que qualquer pessoa veste $^{10 "}$ (Goya Lopes).

"O que me levou a produzir moda afro foi a necessidade de afirmação que estava carente na cidade, os negros não se achavam naquela época. Eu tenho oito anos de marca e não tinha a exposição que hoje tem ${ }^{11 "}$ " (Najara Black).

\footnotetext{
${ }^{10}$ Entrevista concedida a autora em setembro de 2013.
} 
"Eu escolhi a moda afro-brasileira como uma interface de comunicação do meu trabalho, então a marca Julia Vidal está muito relacionada à como essa comunicação é feita $^{12, "}$ (Julia Vidal).

O que podemos observar analisando as falas das estilistas é que todas buscam transmitir seus valores identitários na produção de objetos de moda, fazendo com que essa estética seja referencia para os consumidores.

As cores também são bastante destacadas pelos estilistas da moda afro-brasileira. De acordo com Ivan Porto e Jennifer Francisco (2011) as cores normalmente são fortes, vibrantes e alegres, pois há um costume cultural dos afrodescendentes em elevar o espírito e a alma através do uso de cores. Segundo os autores:

\begin{abstract}
Uma curiosidade é o fato de, ao contrário da maioria dos povos e assim como no Japão, na África o luto é simbolizado pelo branco, mas esse costume não acompanha a diáspora brasileira, pois aqui, devido à catequização dos negros, o luto é simbolizado pelo preto, e o branco significa pureza, luz, paz a mensagem católica de Jesus Cristo, quase sempre retratado como um homem trajando branco (PORTO; FRANCISCO, 2011, p. 12).
\end{abstract}

As cores na moda afro-brasileira são de fundamental importância, pois variam de acordo com os aspectos culturais e com as estações do ano além de serem dotadas de simbologia. Muitos afro-brasileiros gostam de usar roupas coloridas, tecidos leves, com influência africana. Dentre os praticantes do candomblé, há o hábito de usar saias rodadas e lenços na cabeça que podem ser tanto coloridos quanto brancos.

Ivan Porto e Jennifer Francisco (2011, p. 12) afirmam que:

\begin{abstract}
A aplicação das cores também é bem diferente para os europeus e os negros, pois enquanto os brancos buscam uma variada gama de cores e utilizam de pequenos nuances e degrades em suas produções, o africano pratica o extremo o oposto, tem sua classificação cromática definida em três cores o preto, o vermelho e o branco, o que não quer dizer que não utilizem de outras cores, mas cores como verdes e azuis estão dentro da classificação de preto e tons alaranjados, violáceos estão classificados dentro do vermelho e os amarelos no branco e assim observamos sempre uma produção muito contrastante nas produções negras. Visto que o afro-brasileiro se aculturou do amalgama das culturas europeias e africanas, notamos uma facilidade em assimilar ambas as características.
\end{abstract}

\footnotetext{
${ }^{11}$ Entrevista concedida pela estilista Najara Black ao blog Cor \& Estilo. Publicada em 19.11.2013, que pode ser acessada em: https://docs.google.com/document/d/1wtkkb490oEDAytmnH8Mk1a2ncauDm_MYvkrgYxw1qc/edit

${ }^{12}$ Entrevista concedida a autora em janeiro de 2014.
} 
Os autores afirmam ainda que cada orixá do candomblé possui suas cores e elementos de acordo com sua personalidade, e podem ser utilizados como inspiração no desenvolvimento das vestimentas e possíveis associações ao mercado de moda afrobrasileira.

Atualmente, a vestimenta da baiana (figura12) é constituída por elementos multiculturais e simbólicos associados aos costumes do candomblé, que mantém as cores dos orixás:

[...] mantendo as cores dos orixás: branco para Oxalá; azul para Ogum; vermelho para Iansã; vermelho e branco para Xangô; amarelo para Oxum; etc.; além das jóias rituais: fios de contas, correntes em prata, ouro e alpaca, argolas, pulseiras e os turbantes que ajudam na identificação dos orixás (GONÇALVES, 2008, p. 56).

Figura 12 - Baiana no Pelourinho fazendo uso de turbantes, argolas e de uma vestimenta com detalhes nas cores azul e amarelo.

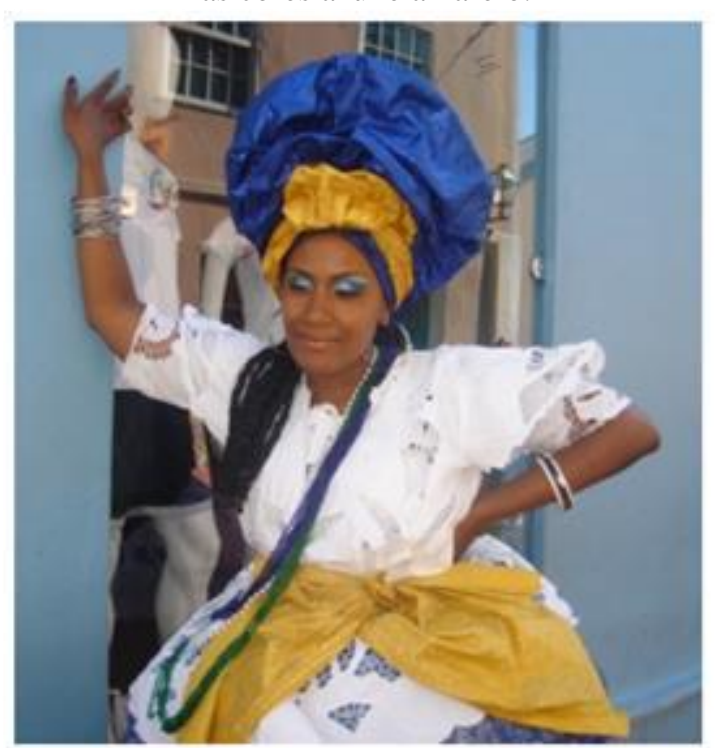

Fonte: Veruska Barreiro Gonçalves (2008, p. 56)

Existem muitos outros produtos que podem ser utilizados para fazer uma releitura da moda étnica e consequentemente da moda afro-brasileira, conforme afirma Raul Lody (2001, p. 42):

$\mathrm{Na}$ indumentária, os panos vistosos, as saias rodadas, os xales da costa, os braceletes, argolões, etc., usados pelos negros na Bahia, têm procedência nigeriana. Outras influências do Sudão muçulmano, como a rodilha ou 
turbante e miçangas e balangandãs, originadas de Angola e do Congo, vêm completar a figura típica da baiana, essa figura popular do Brasil.

Em relação às cores, Julia Vidal afirma que em sua marca isto é uma questão de mercado que é bastante determinante envolvendo as cores encontradas no mercado e outra paleta de cores, que é aquela que a estilista desenvolve com o tingimento artesanal, em que a mesma encontra uma limitação real de possibilidades do uso de cores. Geralmente tem uma gama que vai mais de um amarelado até um terroso, um cinza, sendo cores que não existem em uma paleta tão complexa. Com isso, é possível ir pesquisando novas tonalidades para combinar com os materiais utilizados.

A estilista ressalta ainda que este trabalho artesanal esta associado à pesquisa de materiais que é o resultado possível relacionado com a natureza. Ainda tem um adicional na escolha das cores, que é a temática central da coleção, mantendo o objetivo de vincular o personagem com a vestimenta, assim como seus comportamentos. As cores estão relacionadas com atitudes e disponibilidade do mercado, e a possibilidade de criação de outras cores.

Em sua coleção “O Africano que existe em nós” (Figura 13), Julia Vidal resgata os aspectos históricos da moda brasileira, fazendo alusão aos elementos africanos, utilizando as cores que compõem as aquarelas de Debret ${ }^{13}$, homenageando os negros africanos através da releitura das vestimentas de banho das negras, dos carregadores de leite, dos vendedores de aves, dos negros tigres ${ }^{14}$, dos negros de recado e outros mestiços elegantes.

\footnotetext{
${ }^{13}$ Jean Baptiste Debret, artista plástico francês que veio em excursão ao Brasil em 26 de março de 1816, pintou várias obras que foram importantes na construção do estudo da história e da cultura brasileira.

${ }^{14}$ Negros Tigres: Por volta de 1860 os escravos eram incumbidos de levar as matérias fecais domésticas para as praias. Por esse motivo, passam a serem chamados de "escravos tigres" por causa dos dejetos humanos que sujavam seu corpo.
} 
Figura13 - Coleção "O africano que existe em nós"

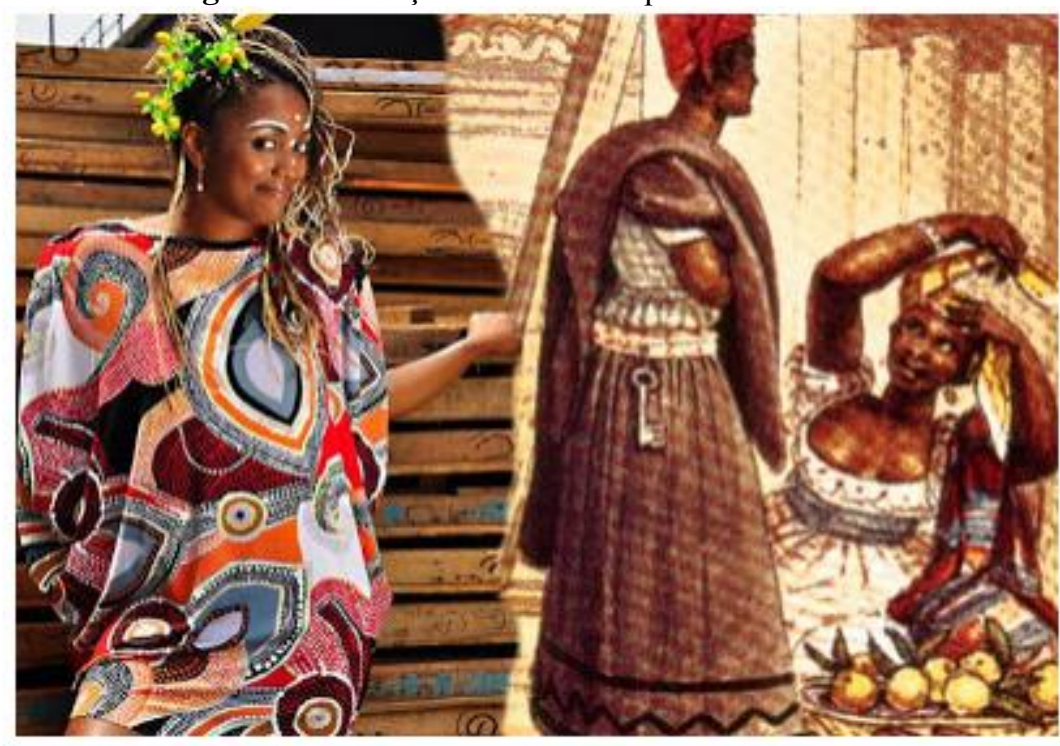

Fonte: Disponível em: <http://www.juliavidal.com.br/portfolio/o-africano-que-existe-em-nos/

Por sua vez, Madalena Cardoso afirma que as cores são muito presentes em sua marca e fazer as misturas dessas cores é algo que diferencia seu produto, entretanto, não trabalha com cores características somente da moda afro-brasileira e também não trabalha diretamente com as cores de tendência de moda disponíveis no mercado. Para ela, o ideal é misturar todas as cores e buscar uma harmonia.

Ao ser questionada sobre como utiliza as cores em sua coleção, Goya Lopes afirma que, quando iniciou utilizava apenas cinco cores, a fim de criar um padrão em seu trabalho e construir uma identidade como designer e alcançar um propósito em seu projeto, que era ser referência a nível estadual, nacional e internacional. Assim permaneceu durante 10 anos utilizando as mesmas cores sem que as pessoas percebessem. Para tanto, Goya ao invés de valorizar as cores, passou a valorizar as formas, destinando seu trabalho a ressaltar o fundo como figura, e a figura como fundo. As cores utilizadas por ela eram preto, vermelho, azul, amarelo e branco. A fim de trabalhar cada uma com uma especificidade, o vermelho era usado de uma maneira mais quente para dar sensualidade, o azul estava associado com o verde e às cores frias, todas elas permaneciam sempre integradas para que seu público pudesse saber que aquela era sua criação sem que necessitasse de uma assinatura propriamente dita.

Para tanto, ela afirma que não quer que seu estilo seja absorvido por outras tendências, pois quer trabalhar com características brasileiras, porém mantendo 
referências afro-brasileiras dentro de um padrão de cores. Ressalta-se aqui a clareza de propósito da estilista, uma coerência que respeita as necessidades da questão afrobrasileira, elementos que são considerados no processo de criação.

Em uma de suas coleções, Goya utilizou cores fortes associadas à cultura africana e acrescentou cores de tendência em contraste, buscando alcançar maior harmonia entre as mesmas. A estilista ressalta que o importante é saber trabalhar as cores de tendência em harmonia com as cores de referencia afro.

Ao analisar outros estilistas, percebe-se que eles fazem uso de uma variedade de cores que fazem referência à cultura africana, cores fortes e vibrantes com preferencia por tons quentes como o vermelho, laranja e o amarelo. Utilizam também cores com referência artesanal, misturando tendências de moda, tingimentos naturais e mix de cores fortes. Os tecidos estampados estão presentes em todas as marcas com padronagens de forte referencia africana ou também afro-brasileira mais voltada para o cotidiano com estampas localizadas que fazem referencia a estática brasileira. Muitos estilistas buscam utilizar referencias naturais, tingimentos com elementos da terra, e utilização de aplicações e bordados.

Essa diferenciação entre as marcas demonstra que cada estilista tem uma maneira de estabelecer e aplicar as cores em suas coleções, alguns prezam por conceitos como sustentabilidade, outros pelo emprego de referências simbólicas.

\section{PARA QUEM ESTÁ DESTINADA?}

Para se compreender o mercado de moda afro-brasileira, torna-se fundamental entender para qual público é destinado o segmento. Para Júlia Vidal, o público alvo da sua marca são mulheres, numa faixa etária mais ou menos de 25 a 55 anos. São pessoas que apresentam formação profissional, que atuam em áreas de sociologia, antropologia, educação. Muitas são professoras, artistas, artistas plásticas, cantoras, jornalistas,

formadoras de opinião e produtoras culturais. É um público bem definido. Inicialmente o público da marca era composto por $80 \%$ de brancos, atualmente este número esta ficando mais "equilibrado", com a valorização dos negros, estes se sentem mais à vontade em consumir, mais interessados em demonstrar o orgulho de querer ser negro. No entanto, a marca não faz distinção para cor de pele, as vestimentas são valorizadas 
pelas mulheres independente da raça, Está voltada a todas as mulheres que se identificam com a cultura afro-brasileira.

Para a estilista, voltado para o mercado de moda afro-brasileira, há um estigma de que as roupas são desenvolvidas em sua maioria para os negros, mas nos dias atuais já existe esse esclarecimento que faz com que a população branca também se identifique com a moda afro-brasileira, e isto tem contribuído para que os negros tenham mais orgulho de sua raça e sua cultura. Entende-se com isso que alguns negros se sentem mais à vontade em valorizar sua cultura e consumir os produtos do mercado de moda afro a partir do momento que observam a população branca usar os mesmos produtos.

Julia Vidal enfatiza ainda que existe uma diferença entre o que é o mercado consumidor e o que é o público-alvo. Além das pessoas já citadas, o público para ela também engloba os turistas, pois sua marca é um atrativo muito grande para eles, em decorrência dos trabalhos com uma riqueza cultural e histórica maior então estes indivíduos valorizam muito estas peças.

Por sua vez, o público alvo na marca Negrif, da estilista Madalena Cardoso, atende pessoas do Brasil e do mundo todo, não apenas de Salvador. No entanto, conforme a estilista descreve em entrevista, "as peças são direcionadas para pessoas que tem identidade, que desejam coisas diferentes, que não são produzidas em série, e que consequentemente valorizam o único".

A estilista relata que os maiores espaços de apresentação da moda afro-brasileira são as ruas. Para tanto, não trabalha com pret-a-porter ${ }^{15}$, pois não foca no mercado de produção em série, preferindo trabalhar com peças únicas em tecido. Em determinadas ocasiões, trabalha com peças sob medida e faz trabalhos com estamparias exclusivas, que atualmente já ultrapassam 50 desenhos diferentes criados especialmente para marca.

Já, para Goya Lopes existem muitas vertentes que a moda afro-brasileira pode atender: a do cotidiano; a do hip hop; a urbana, lembrando os EUA, dentro da linguagem dos anos 70; e a vertente religiosa. A estilista afirma que muitas pessoas procuram vestimentas religiosas, pois vão a festas e necessitam se enquadrar neste grupo.

\footnotetext{
${ }^{15}$ Pret-a-porter: A roupa fabricada em serie ou em grande escala como estamos acostumados a encontrar em lojas, sem teor de exclusividade.
} 
Goya também afirma que a moda afro-brasileira é para todos e ressalta que desde o início de sua carreira promove esta perspectiva. Isto ocorre, pois, seu projeto como afrodescendente era criar uma moda da cultura afro que pudesse ser utilizada por qualquer pessoa. Para tanto, constatou que isto envolveria a pessoa que se sensibilizaria com a simbologia afro que para ela seriam três grupos:

- os próprios afrodescendentes: no sentido de cultivar essa raiz e incentivar o consumo e a vestimenta que se enquadra na historia dos seus antepassados.

- os sensibilizantes com a cultura independente de ser afrodescendente.

- as pessoas que gostam da estética como os turistas, por exemplo.

Com base nas informações das paginas das redes sociais dos estilistas ou nos sites dos próprios estilistas foi possível observar quem é o público-alvo deles, e foi possível constatar que as marcas não possuem o estigma de que a moda afro-brasileira é uma moda destinada unicamente para a população negra, uma vez que os mesmos mantem como público alvo pessoas negras e brancas que se identificam com o estilo afro.

Os estilistas não acreditam que fazer uma moda com referencias afro restringe o público, deixando claro que a moda afro-brasileira não é exclusiva da população afrodescendente, ela é pensada com base nas raízes e origens negras, mas não é destinada somente aos negros, podendo ser valorizada e consumida por qualquer pessoa que se identifique com a estética.

Com a globalização, Júlia Vidal ressalta ainda que é fundamental ampliar o recorte conceitual em termos de nicho, uma vez que o mercado da moda afro-brasileira é muito complexo e não existe uma fórmula para estar inserido nele, necessitando focar na questão da identidade, saber quais são os materiais utilizados nas coleções; qual o conceito; dentro desse conceito o que a marca vai trabalhar; quais são as cores e qual o tipo de modelagem que vai ser trabalhada. Isso tudo define bem o conceito e faz com que o mercado entenda mais rapidamente o trabalho dos estilistas.

Goya Lopes também afirma que a moda afro-brasileira necessita da criação de padrões que devem ser seguidos, para nortear futuros criadores que queiram adentrar a esse nicho de mercado, criando um estilo que sirva de referencia para outros estilistas e aproveitar isso servindo como uma imagem do Brasil. Esta estilista aponta que para se 
obter um aproveitamento do mercado é fundamental valorizar a cultura, com essa questão da diáspora, respeitando a miscigenação.

Analisando as falas das estilistas, podemos complementar que existe uma vontade de crescimento, e que essas profissionais reúnem esforços, se agrupando, estudando e evoluindo para que a moda afro-brasileira tenha maior visibilidade no mercado de moda.

\section{CONCLUSÃO}

Diante dos referenciais levantados neste artigo, afirma-se que a moda afrobrasileira apresenta grande exponencial para crescimento no mercado brasileiro. Com base na pesquisa com as estilistas foi possível constatar que existe sim um segmento de moda-afro-brasileira, e é um segmento que efetivamente atua no mercado brasileiro e que está em expansão apesar de ainda existir muitos obstáculos.

Muitos dos estilistas ainda precisam superar os desafios impostos por uma sociedade repleta de preconceito e por um mercado que não oferece oportunidades relevantes para que a moda afro-brasileira possa obter um crescimento significativo. Para driblar estas dificuldades, os estilistas estão buscando alinhar suas criações com a estética da indústria da moda, porém mantendo a identidade afro-brasileira como conceito principal. Com isso percebe-se que a moda afro-brasileira, embora receba influência dos elementos simbólicos desta matriz, pode ser usada por qualquer grupo social que se identifique com suas roupas ou seus acessórios, sendo efetivamente uma moda para todos. 


\section{Referências}

BOURDIEU, Pierre. Questões de sociologia. Rio de Janeiro: Marco Zero, 1983.

GIDDENS, Anthony. Modernidade e identidade. Rio de Janeiro: Jorge Zahar, 2002.

GONÇALVES, Veruska Barreiros. Moda afro-baiana: comunicação e identidade através da estética afro (2008) Disponível em: <http://livros01.livrosgratis.com.br/cp101992.pdf> Acesso em: 15 de mai. 2016

LODY, Raul Giovanni da Motta. Cabelos de axé: identidade e resistência. Rio de Janeiro: Ed. Senac Nacional, 2004.

LODY, Raul Giovanni da Motta. Jóias de Axé: fios de contas e outros adornos do corpo: a joalheria afro brasileira. Rio de Janeiro: Bertrand Brasil, 2001.

PORTO, Ivan Luis Sérvulo; FRANCISCO, Jennifer K. Silva. Moda Ayê: Guia de elementos afro-brasileiros para moda (2011) Disponível em: <http://www.esocite.org.br/eventos/tecsoc2011/cd-anais/arquivos/pdfs/artigos/gt022modaaye.pdf> Acesso em: 10 de mai. 2016

SAHLINS, Marshall. Cultura e razão prática. Rio de Janeiro: Zahar, 1979.

SANT'ANNA, Patrícia. Moda: uma apaixonante história das formas (2009) Disponível em: <http://cienciaecultura.bvs.br/pdf/cic/v61n1/a20v61n1.pdf> Acesso em: 10 de mar. 2016 